\title{
A novel DSPP mutation causes dentinogenesis imperfecta type II in a large Mongolian family
}

Haihua Bai ${ }^{1,2}$, Hasi Agula', Qizhu Wu², Wenyu Zhou ${ }^{3}$ Yujing Sun ${ }^{3}$, Yue Qi ${ }^{3}$, Suya Latu², Yujie Chen², Jiri Mutu², Changchun Qiu ${ }^{3 *}$

\begin{abstract}
Background: Several studies have shown that the clinical phenotypes of dentinogenesis imperfecta type II (DGI-II) may be caused by mutations in dentin sialophosphoprotein (DSPP). However, no previous studies have documented the clinical phenotype and genetic basis of DGI-II in a Mongolian family from China.

Methods: We identified a large five-generation Mongolian family from China with DGI-II, comprising 64 living family members of whom 22 were affected. Linkage analysis of five polymorphic markers flanking DSPP gene was used to genotype the families and to construct the haplotypes of these families. All five DSPP exons including the intron-exon boundaries were PCR-amplified and sequenced in 48 members of this large family.

Results: All affected individuals showed discoloration and severe attrition of their teeth, with obliterated pulp chambers and without progressive high frequency hearing loss or skeletal abnormalities. No recombination was found at five polymorphic markers flanking DSPP in the family. Direct DNA sequencing identified a novel $A \rightarrow G$ transition mutation adjacent to the donor splicing site within intron 3 in all affected individuals but not in the unaffected family members and 50 unrelated Mongolian individuals.
\end{abstract}

Conclusion: This study identified a novel mutation (IVS3+3A $\rightarrow \mathrm{G}$ ) in DSPP, which caused DGI-II in a large Mongolian family. This expands the spectrum of mutations leading to DGI-II.

\section{Background}

Dentinogenesis imperfecta type II (DGI-II) (OMIM \# 125490) is an autosomal dominant dental disorder with a complete penetrance that affects both the primary and the permanent teeth [1]. DGI-II is characterized by amber and opalescent teeth, abnormal dentine leading to obliteration of the pulp chamber, and enamel that, although unaffected, tends to fracture. This causes the dentine to undergo rapid attrition, leading to a marked shortening of the teeth. The gene DSPP is located in the 6.6-cM D4S2691-D4S2692 interval at 4q21 and encodes a precursor protein, which is cleaved to yield dentine sialoprotein (DSP) and dentine phosphoprotein (DPP) [2-4]. A nonsense mutation in DSPP has been reported to cause DGI-II in a Chinese family [5] and other DSPP mutations have subsequently been demonstrated in

\footnotetext{
* Correspondence: jrmt@sina.com; cc_qiu@yahoo.com.cn

${ }^{2}$ Inner Mongolia University for the Nationalities, Tongliao 028000, China ${ }^{3}$ National Laboratory of Medical Molecular Biology, Institute of Basic Medical Sciences, Chinese Academy of Medical Sciences/Peking Union Medical College (CAMS/PUMC), 5 Dong Dan San Tiao, Beijing 100005, China
}

Chinese families with DGI-II [6-9]. In addition, families with DGI-II in other countries have been reported with mutations in DSPP [10-15]. However, the genetic basis of DGI-II in Mongolian families has not been explored before. In the present study, we describe a large, fivegeneration Mongolian family with DGI-II and report a novel DSPP mutation in this family.

\section{Methods \\ Patients}

We identified a large, five-generation Mongolian family with DGI-II consisting of 64 living family members, of which 22 were affected (Figure 1). All living members were examined clinically and taken for panoramic dental tomograms. The clinical and radiographic images were published under the patients' written permission. The study "Gene Research on Dentinogenesis Imperfecta in Mongolian Families" was approved by the Research Ethics Committee of Peking Union Medical College. 


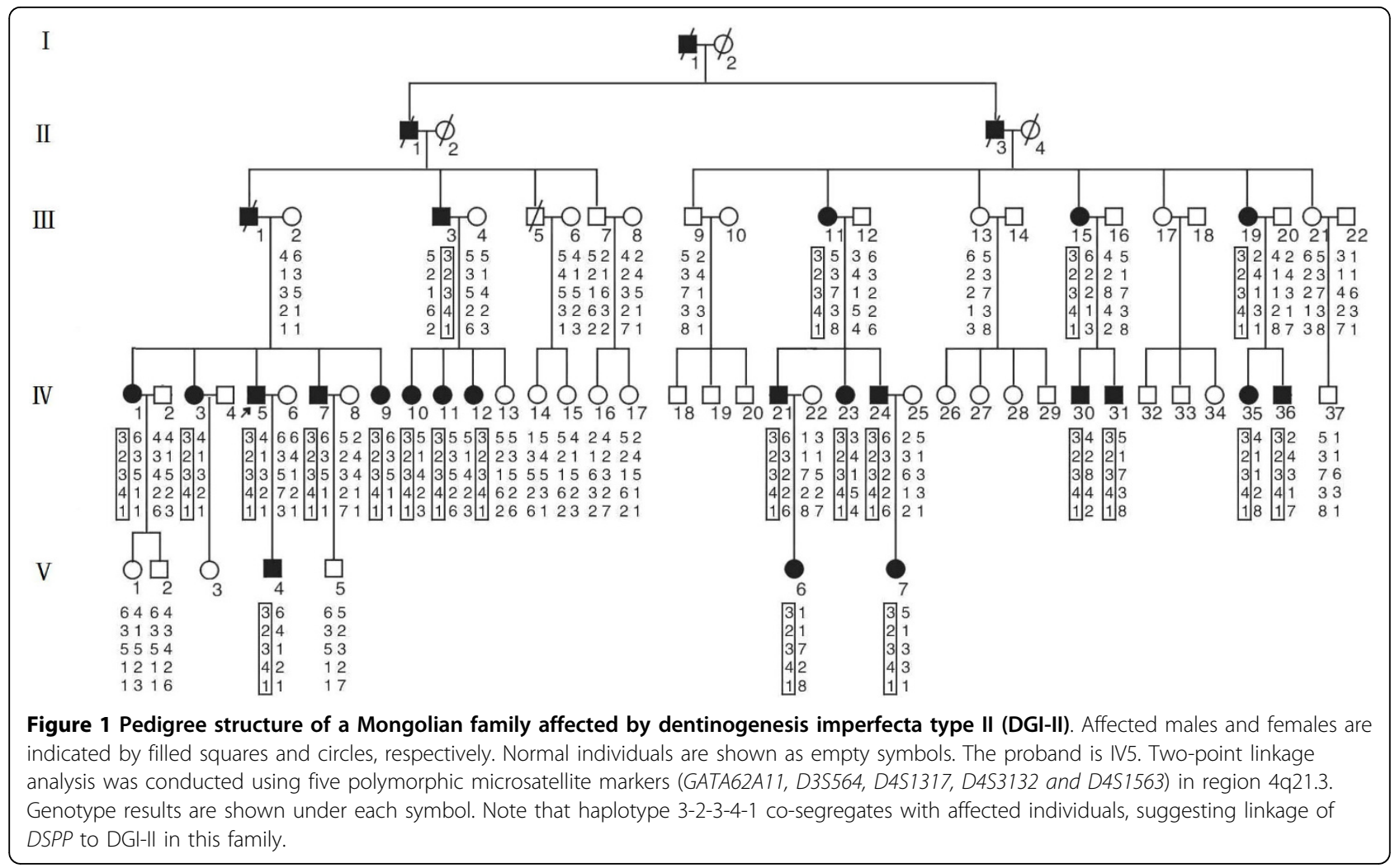

\section{DNA extraction}

Peripheral blood leukocytes were collected from 48 of the 64 family members, and human genomic DNA was extracted by using phenol - chloroform followed by ethanol precipitation.

\section{Genetic linkage and haplotype analysis}

Two-point linkage analysis was conducted using five polymorphic markers (GATA62A11, D3S564, D4S1317, $D 4 S 3132$ and $D 4 S 1563$ ) at 4q21.3. LOD scores were calculated using the MLINK program of the LINKAGE package. The parameters used for linkage analysis were autosomal dominant inheritance, complete penetrance, a mutation rate of zero, equal male-female recombination rates, equal allele frequency, and a disease allele frequency of 1 in 10,000.

\section{Sequence analysis of DSPP}

Mutation screening was carried out using direct DNA sequence analysis. The exons of the DSPP gene were amplified by primers flanking the exon-intron boundaries (Table 1). Exon 4 was amplified into two, and Exon 5 was amplified into six fragments. PCR conditions for exons 1-5 were as followlling: a 5-min initial denaturation at $94^{\circ} \mathrm{C}, 35$ cycles of 1 - min denaturation at $94^{\circ} \mathrm{C}, 1-\mathrm{min}$ annealing at $58^{\circ} \mathrm{C}, 58^{\circ} \mathrm{C}, 50^{\circ} \mathrm{C}, 60^{\circ} \mathrm{C}, 60^{\circ}$ $\mathrm{C}, 60^{\circ} \mathrm{C}, 64^{\circ} \mathrm{C}, 60^{\circ} \mathrm{C}, 60^{\circ} \mathrm{C}, 55^{\circ} \mathrm{C}$, and $55^{\circ} \mathrm{C}$, respectively, and a 1-min extension at $72^{\circ} \mathrm{C}$, and a 5-min final extension at $72^{\circ} \mathrm{C}$. PCR product were sequenced by Beijing AuGCT Biotechnology Co., Ltd http://http:www.augct. com.

We determined the sequences of all five exons and the exon flanking sequences of DSPP from 48 of affected and unaffected individuals in this family. The mutaton sites of 50 unrelated healthy Mongolian controls also were sequenced directly.

\section{Prediction of the mutation effect}

In order to investigate whether the mutation will affect the splice donor site of exon 3, we used the BDGP site http://www.fruitfly.org/seq_tools/splice.html to predicte the effect of gene mutation on the splicing site of the DSPP [16].

\section{Results}

In the five-generation Mongolian family with DGI-II, the proband was a man aged 32 (Figure 1, IV5 ). His permanent teeth showed a shade of brown and almost complete attrition of the enamel layer without a history of periapical infections. All affected individuals showed discoloration and severe attrition of their teeth with obliterated pulp chambers. In addition, the enamel, although unaffected, had tended to fracture, causing the dentine to undergo rapid attrition, leading to a marked 
Table 1 Primers used for amplification and sequencing of the DSPP gene

\begin{tabular}{|c|c|c|c|}
\hline Exon & Forward primer sequence $\left(5^{\prime}-3^{\prime}\right)$ & Reverse primer sequence $\left(5^{\prime}-3^{\prime}\right)$ & $\begin{array}{c}\text { Annealing Temperature } \\
\left({ }^{\circ} \mathrm{C}\right)\end{array}$ \\
\hline 1 & TCACCAAGTGAAGGAAGTGG & AAAGCCCAAGGTGGATTITT & $58^{\circ} \mathrm{C}$ \\
\hline 2 & GATGCCCCCATAACCACACC & CTCCATGACTTCTGGGCATT & $58^{\circ} \mathrm{C}$ \\
\hline 3 & AAGAACCTITTCAATAGCCAGT & TGGAGAAGTTAATGGAATGTAGCAAC & $50^{\circ} \mathrm{C}$ \\
\hline $4-1$ & TGCAATTTGCTTTCCTTCAAG & TGTTATTGCTTCCAGCTACTTGAG & $60^{\circ} \mathrm{C}$ \\
\hline $4-2$ & CAATGAGGATGTCGCTGTTG & TGCCATTGAAAGAAATCAGC & $60^{\circ} \mathrm{C}$ \\
\hline $5-1$ & TTCTITCCTCCATCCTTCCATAG & TGTCATCATTCCCATTGTTACC & $60^{\circ} \mathrm{C}$ \\
\hline $5-2$ & CAAAAGGAGCAGAAGATGATGAC & TTGCTGCTGTCTGACTTGCT & $64^{\circ} \mathrm{C}$ \\
\hline $5-3$ & CAAATCAGACAGTGGCAAAGGTAAAT & CACTGCTATTGCTGCTGTCGTTGCT & $60^{\circ} \mathrm{C}$ \\
\hline $5-4$ & GACAGCAGTAATAGTAACAGCAGCG & GCTGTCGCTGCTATTGCTATCACTG & $60^{\circ} \mathrm{C}$ \\
\hline $5-5$ & GCAGTGACAGCAACGAAAGCAGCAAT & GTTGTTACCGTTACCAGACTTGCTC & $55^{\circ} \mathrm{C}$ \\
\hline $5-6$ & TGACAGCACATCTGACAGCAAT & TCCCCCAGTTGTTITGTT & $55^{\circ} \mathrm{C}$ \\
\hline
\end{tabular}

shortening of the teeth. Both the primary and the permanent teeth were affected (Figure 2). No high-frequency hearing loss or obvious skeletal abnormalities were found in any of the affected individuals.

Through linkage analysis we obtained a maximal LOD score of 6.06 for marker D3S564 at $\theta=0.00$, thereby demonstrating definitive linkage. Haplotype analysis showed that haplotype 3-2-3-4-1 cosegregated with the disease in this family, indicating that the disease locus was linked to the chromosome region harboring $D S P P$, and that DSPP was a candidate gene (Figure 1).

Mutation screening showed a novel, functional $A \rightarrow G$ transition mutation adjacent to the donor splicing site (GT) within intron 3 of DSPP in all affected individuals, whereas this mutation was not found among the unaffected individuals in the family (Figure 3). Furthermore, we did not find this mutation in 50 unrelated, healthy Mongolian controls. a.

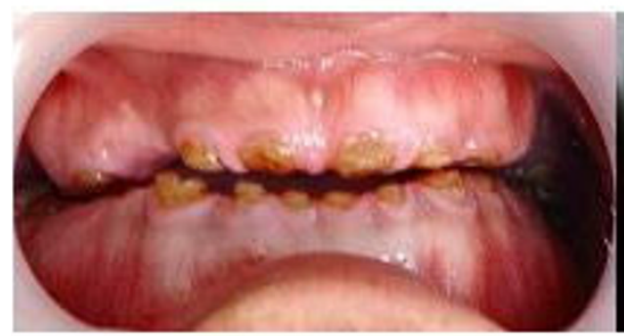

c.

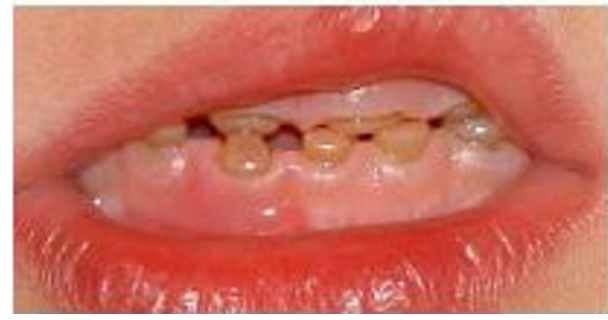

b.

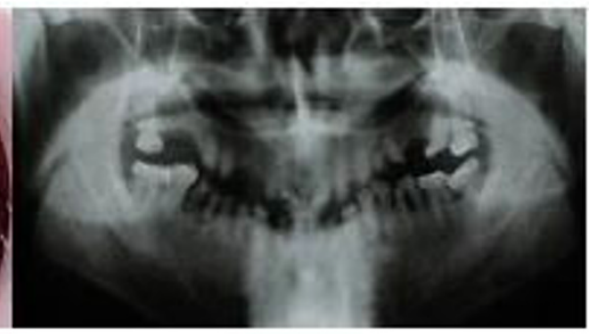

d.

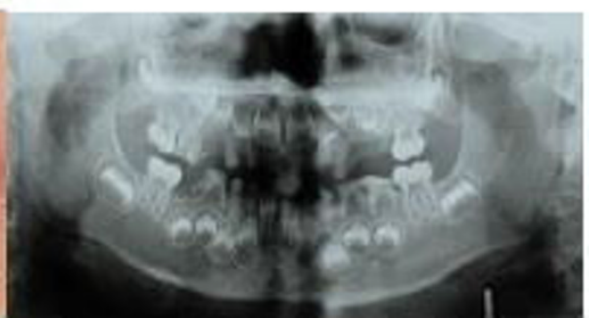

Figure 2 Clinical analysis of dentinogenesis imperfecta type II (DGI-II). The proband (IV5) is a man aged 32. His permanent teeth showed a shade of brown and almost complete attrition of the enamel layer without a history of periapical infections(a and b). Dentition of the 5-year-old son of the proband. His primary teeth had shown normal timing of eruption, but shortly thereafter become brownish and small due to cracking of the enamel and attrition of dentin. At the time of examination, his first permanent molars had just emerged and still showed an intact enamel(c and d). 


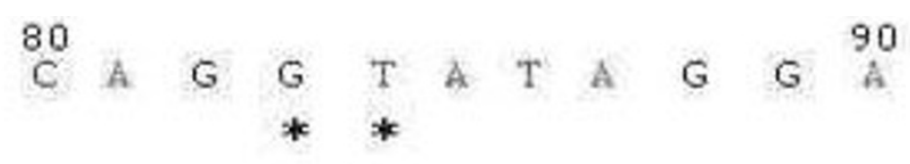

\section{Unaffected}
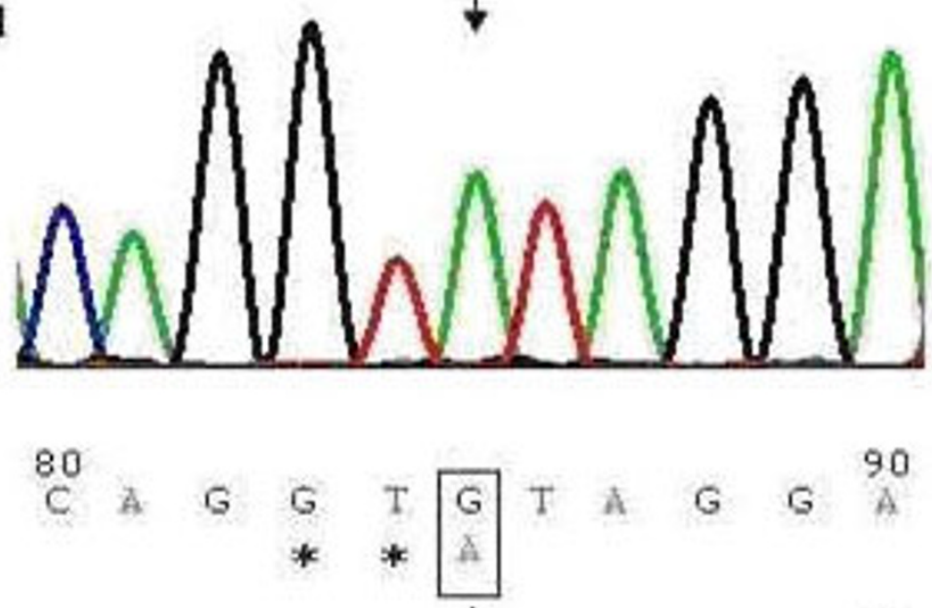

\section{affected}

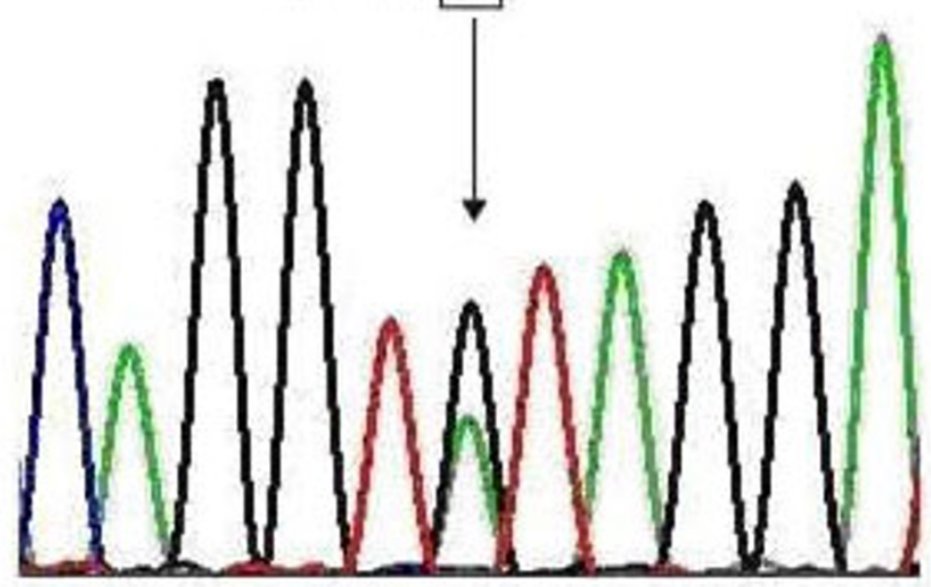

\section{*The donor splice site.}

Figure 3 Identification of a novel mutation. An $A \rightarrow G$ transition adjacent to the donor splicing site (GT) within intron 3 of DSPP was detected in all affected individuals, whereas this mutation was not detected in unaffected individuals of the DGI-II Mongolian family or in unrelated healthy Mongolian controls. DNA sequences for a normal family member (upper panel) and the proband IV5 (lower panel).

The available splicing site prediction software, the BDGP site, was utilized to predict the consequence of the mutation (IVS3 $+3 \mathrm{~A} \rightarrow \mathrm{G}$ ) in DSPP, the splice donor site of exon3 went from a score of 0.89 to $<0$.

\section{Discussion}

We identified a novel mutation (IVS3 $+3 \mathrm{~A} \rightarrow \mathrm{G}$ ) in $D S P P$ in a large Mongolian family suffering from dentinogenesis imperfecta II (DGI-II). This novel mutation (IVS3
$+3 \mathrm{~A} \rightarrow \mathrm{G}$ ) resulted in a donor splicing site change from wild-type GTAT to mutated GTGT in one of the two DSPP alleles that co-segregate in affected individuals. This mutation did not exist in unaffected family members or in an additional 50 healthy Mongolian controls. These results suggest that the $A \rightarrow G$ mutation caused DGI-II in this Mongolian family.

DGI-II is a clinically heterogeneous disorder caused by DSPP mutations [7,17-19]. Previous studies have 
reported DGI-II families with a mis-sense mutation in exon 2 [6], a nonsense mutation in exon 3 [5], splicing site mutations in intron $3+1[6,9]$ and a frameshift mutation in intron 2 [9]. However, the molecular mechanisms by which DSPP mutations cause DGI-II are still unclear. In this Mongolian family, we speculate that the novel mutation is likely to produce a new splicing site and destroy the original splicing site within intron 3. This mutation may result in the abnormal intron splicing and lead to exon-skipping with a loss of exon 3, which encodes part of dentin sialoprotein protein. Because tissue samples from this family were unavailable, we were unable to prepare mRNA from the affected individuals to determine the sequences of DSPP transcripts.

To our knowledge, this study is the first report of a novel DSPP mutation causing DGI-II in a Mongolian family from China. This mutation differs from those found previously in other Chinese families and in families of other ethnic groups. Mongolians represent one of the major ethnic minority groups in China. They reside on the Inner Mongolian grassland in the northeast of China, where they live a nomadic lifestyle. This Mongolian family, whose forebears lived on the Horqin grassland in the eastern part of Inner Mongolia for many generations, is a relatively homogeneous population with characteristics that are advantageous for genetic research, including low divorce rate, limited mobility, consistent dietary habits and favorable environmental factors.

\section{Conclusion}

This study documents a novel $A \rightarrow G$ transition mutation adjacent to the donor splicing site (GT) within intron 3 of DSPP that causes DGI-II in a large Mongolian family. This expands the spectrum of mutations that cause DGI-II.

\section{Abbreviations}

DGl: dentinogenesis imperfecta; DPP: dentine phosphoprotein; DSP: dentine sialoprotein; DSPP: dentin sialophosphoprotein

\section{Acknowledgements \\ The authors thanks the volunteers for participating in this study, all the doctors in the Stomatological Department of the Affiliated Hospital, Inner Mongolia University for the Nationalities, Tongliao City for collecting samples, and our colleagues for excellent technical assistance. This study was supported by grants from the National Science Foundation Committee of China (30560060) and the National Science Technology program (2006 BAl 19B07).}

\section{Author details}

${ }^{1}$ Inner Mongolia University, Huhhot 010021, China. ${ }^{2}$ Inner Mongolia University for the Nationalities, Tongliao 028000, China. ${ }^{3}$ National Laboratory of Medical Molecular Biology, Institute of Basic Medical Sciences, Chinese Academy of Medical Sciences/Peking Union Medical College (CAMS/PUMC), 5 Dong Dan San Tiao, Beijing 100005, China.

\section{Authors' contributions}

HB designed the study and family recruitment, performed the linkage analysis, drafted the manuscript and obtained funding. HA supervised the study design. QW conducted clinical diagnoses and family recruitment. JM supervised the study and family recruitment. CQ did the genetic design, supervised the study and obtained funding. All other authors provided technical assistance, and all authors read and approved the final manuscript.

\section{Competing interests}

The authors declare that they have no competing interests.

Received: 8 May 2009

Accepted: 10 February 2010 Published: 10 February 2010

\section{References}

1. Witkop CJ: Hereditary defects in enamel and dentine. Acta Genet Stat Med 1957, 7(1):236-239.

2. Crosby AH, Scherpbier-Heddema T, Wijmenga C, Altherr MR, Murray JC, Buetow KH, Dixon MJ: Genetic mapping of the dentinogenesis imperfecta type II locus. Am J Hum Genet 1995, 57(4):832-839.

3. MacDougall M: Refined mapping of the human dentine sialophosphoprotein (DSPP) gene within the critical dentinogenesis imperfecta type II and dentine dysplasia type II loci. Eur J Oral Sci 1998, 106(Suppl 1):227-233.

4. MacDougall M, Simmons D, Luan X, Nydegger J, Feng J, Gu TT: Dentin phosphoprotein and dentin sialoprotein are cleavage products expressed from a single transcript coded by a gene on human chromosome 4. Dentine phosphoprotein DNA sequence determination. J Biol Chem 1997, 272(2):835-842.

5. Zhang X, Zhao J, Li C, Gao S, Qiu C, Liu P, Wu G, Qiang B, Lo WH, Shen Y: DSPP mutation in dentinogenesis imperfecta Shields type II. Nat Genet 2001, 27(2):151-152.

6. Xiao S, Yu C, Chou X, Yuan W, Wang Y, Bu L, Fu G, Qian M, Yang J, Shi Y, Hu L, Han B, Wang Z, Huang W, Liu J, Chen Z, Zhao G, Kong X: Dentinogenesis imperfecta 1 with or without progressive hearing loss is associated with distinct mutations in DSPP. Nat Genet 2001, 27(2):201-204.

7. Song Y, Wang C, Peng B, Ye X, Zhao G, Fan M, Fu Q, Bian Z: Phenotypes and genotypes in 2 DGI families with different DSPP mutations. Oral Surg Oral Med Oral Pathol Oral Radiol Endod 2006, 102(3):360-374.

8. Zhang X, Chen L, Liu J, Zhao Z, Qu E, Wang X, Chang W, Xu C, Wang QK, Liu M: A novel DSPP mutation is associated with type II dentinogenesis imperfecta in a Chinese family. BMC Med Genet 2007, 8:52.

9. Wang H, Hou Y, Cui Y, Huang Y, Shi Y, Xia X, Lu H, Wang Y, Li X: A novel splice site mutation in the dentin sialophosphoprotein gene in a Chinese family with dentinogenesis imperfecta type II. Mutat Res 2009, 662(1-2):22-27.

10. Rajpar MH, Koch MJ, Davies RM, Mellody KT, Kielty CM, Dixon MJ: Mutation of the signal peptide region of the bicistronic gene DSPP affects translocation to the endoplasmic reticulum and results in defective dentine biomineralization. Hum Mol Genet 2002, 11(21):2559-2565.

11. Kim JW, Nam SH, Jang KT, Lee SH, Kim CC, Hahn SH, Hu JC, Simmer JP: A novel splice acceptor mutation in the DSPP gene causing dentinogenesis imperfecta type II. Hum Genet 2004, 115(3):248-254.

12. Malmgren B, Lindskog S, Elgadi A, Norgren S: Clinical, histopathologic, and genetic investigation in two large families with dentinogenesis imperfecta type II. Hum Genet 2004, 114(5):491-498.

13. Kim JW, Hu JC, Lee Jl, Moon SK, Kim YJ, Jang KT, Lee SH, Kim CC, Hahn SH, Simmer JP: Mutational hot spot in the DSPP gene causing dentinogenesis imperfecta type II. Hum Genet 2005, 116(3):186-191.

14. Holappa H, Nieminen P, Tolva L, Lukinmaa PL, Alaluusua S: Splicing site mutations in dentine sialophosphoprotein causing dentinogenesis imperfecta type II. Eur J Oral Sci 2006, 114(5):381-384.

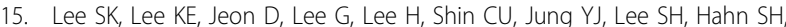
Kim JW: A novel mutation in the DSPP gene associated with dentinogenesis imperfecta type II. J Dent Res 2009, 88(1):51-55.

16. Reese MG, Eeckman FH, Kulp D, Haussler D: Improved Splice Site Detection in Genie. J Comp Biol 1997, 4(3):311-23.

17. MacDougall M, Dong J, Acevedo AC: Molecular basis of human dentine diseases. Am J Med Genet A 2006, 140(23):2536-2546. 
18. Kim JW, Simmer JP: Hereditary dentine defects. J Dent Res 2007, 86(5):392-399.

19. Acevedo AC, Santos LJ, Paula LM, Dong J, MacDougall M: Phenotype characterization and DSPP mutational analysis of three Brazilian dentinogenesis imperfecta type II families. Cells Tissues Organs 2009, 189(1-4):230-236.

\section{Pre-publication history}

The pre-publication history for this paper can be accessed here:http://www. biomedcentral.com/1471-2350/11/23/prepub

doi:10.1186/1471-2350-11-23

Cite this article as: Bai et al: A novel DSPP mutation causes

dentinogenesis imperfecta type II in a large Mongolian family. BMC

Medical Genetics 2010 11:23.

Submit your next manuscript to BioMed Central and take full advantage of:

- Convenient online submission

- Thorough peer review

- No space constraints or color figure charges

- Immediate publication on acceptance

- Inclusion in PubMed, CAS, Scopus and Google Scholar

- Research which is freely available for redistribution

Submit your manuscript at www.biomedcentral.com/submit 